\title{
Interactive Visual Support for Metagenomic Contig Binning
}

Bertjan Broeksema ${ }^{\star}$, Fintan McGee ${ }^{\star}$, Magdalena Calusinka ${ }^{\&}$, Mohammad Ghoniem ${ }^{\star}$
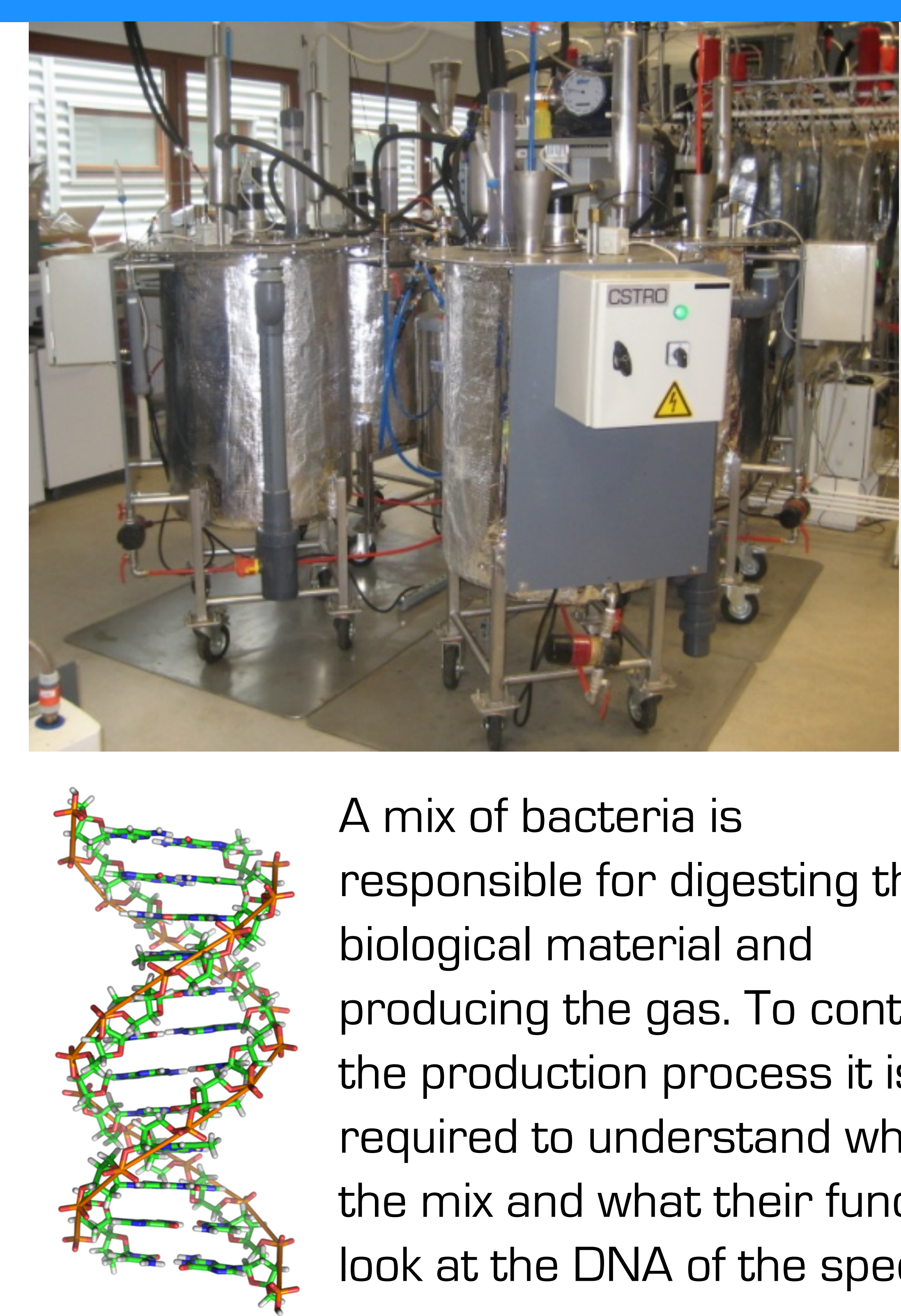

A mix of bacteria is

responsible for digesting the biological material and producing the gas. To control the production process it is required to understand which species

Biogas is becoming increasingly important as a sustainable alternative for conventional energy sources. A good understanding of the biological aspects is crucial to optimize the production. the mix and what their function is. For this, biologists look at the DNA of the species found in a biogas tank.
Shotgun sequencing methods, result in many small fragments of DNA, belonging to the various species. Multiple samples are taken over time.
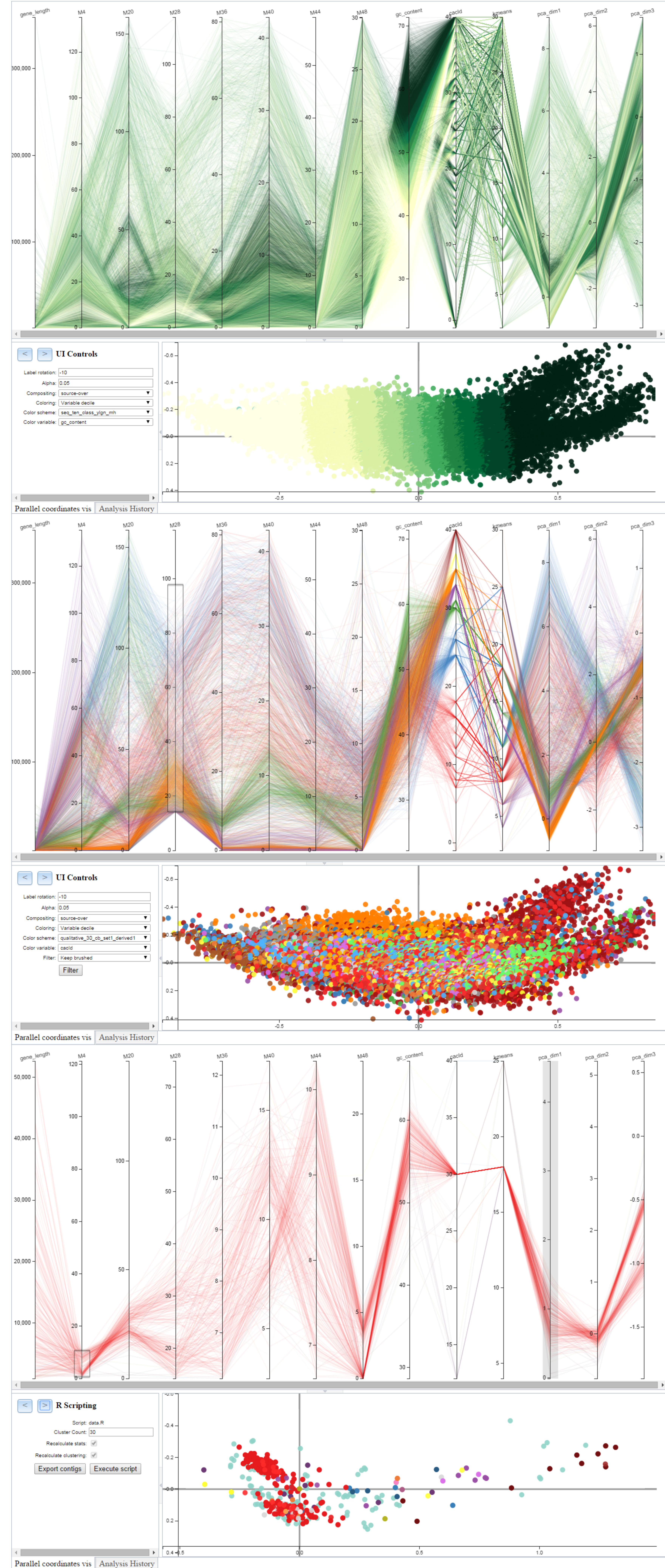

\section{Future Directions and Challenges}

- Visualization of uncertainty data, reflecting the uncertainty of the provenance of DNA sequences.

- Contig aggregation and bundling to reduce overdrawing - Integration and evaluation of contemporary automatic binning approaches.

- User evaluation using subject matter experts. 